\title{
Derivatif Radial Anomali Gravitasi untuk Identifikasi Zona Sesar
}

\author{
${ }^{1}$ Muhammad Zuhdi Ronodirdjo, ${ }^{2}$ Aris Doyan, ${ }^{3}$ Sutrio, ${ }^{4}$ Wahyudi, ${ }^{5}$ Muh Makhrus \\ ${ }^{1}$ Prodi Pendidikan Fisika, FMIPA, Universitas Mataram, Jln. Majapahit no 62, Mataram, \\ NTB, 83000 \\ Email Korespondensi: mzuhdi@unram.ac.id
}

\begin{tabular}{|c|c|}
\hline Article Info & Abstract \\
\hline $\begin{array}{l}\text { Article History } \\
\text { Received: October } \\
\text { Revised: November } \\
\text { Published: Desember }\end{array}$ & \multirow{2}{*}{$\begin{array}{l}\text { Radial Derivative of Gravity Anomaly for Identification of Fault Zone. Fault } \\
\text { is a displacement of the land with a certain direction and shift that triggers an } \\
\text { earthquake. The existence of faults that are not visible on the surface can be } \\
\text { identified by measuring the gravity anomaly above the earth's surface around } \\
\text { the fault zone. This study was conducted with the aim of testing the } \\
\text { effectiveness of radial derivatives for identification of fault zones, i.e the } \\
\text { presence and positions of faults. Radial derivative is a horizontal derivative of } \\
\text { the earth's gravity anomaly value with the radial direction away from a certain } \\
\text { point that is considered as the radial center. Gravity anomaly data used in this } \\
\text { study is synthetic data from computer calculations using the principle of } \\
\text { forward modeling from a fault model. This model is in the form of a } \\
\text { displacement of the rocks making up the soil at a depth of } 100 \mathrm{~m} \text { with a vertical } \\
\text { shift direction of } 4 \text { with an area of the fault zone } 600 \mathrm{~m} x 600 \mathrm{~m} \text { or } 360,000 \\
\text { m2. This synthetic gravity data is then performed a radial derivative treatment. } \\
\text { The results of this study show that radial derivatives are able to identify the } \\
\text { presence and position of the fault. }\end{array}$} \\
\hline $\begin{array}{l}\text { Keywords } \\
\text { writing instructions; } \\
\text { prism journal; } \\
\text { article template }\end{array}$ & \\
\hline Informasi Artikel & Abstrak \\
\hline $\begin{array}{l}\text { Sejarah Artikel } \\
\text { Diterima: Oktober } \\
\text { Direvisi: November } \\
\text { Dipublikasi: Desember }\end{array}$ & \multirow{2}{*}{$\begin{array}{l}\text { Sesar adalah patahan tanah dengan arah dan pergeseran tertentu yang memicu } \\
\text { terjadinya gempa bumi. Keberadaan sesar yang tidak tampak di permukaan } \\
\text { dapat diidentifikasi dengan mengukur anomali gravitasi di atas permukaan } \\
\text { bumi di sekitar zona sesar. Penelitian ini dilakukan dengan tujuan untuk } \\
\text { menguji efektivitas derivative radial untuk identifikasi zona sesar, yaitu } \\
\text { keberadaan sesar dan posisi sesar. Derivatif radial adalah derivatif horizontal } \\
\text { dari nilai anomali gravitasi bumi dengan arah radial menjauhi titik tertentu } \\
\text { yang dianggap sebagai pusat radial. Data anomali gravitasi yang dipakai pada } \\
\text { penelitian ini adalah data sintetis hasil perhitungan komputer dengan prinsip } \\
\text { forward modeling (pemodelan kedepan) dari suatu model sesar. Model ini } \\
\text { berupa patahan batuan penyusun tanah pada kedalaman } 100 \mathrm{~m} \text { dengan arah } \\
\text { pergeseran vertikal sebesar } 4 \text { m dengan luas area zona sesar } 600 \text { m x } 600 \mathrm{~m} \\
\text { atau } 360.000 \mathrm{~m}^{2} \text {. Data gravitasi sintetis ini kemudian diberi perlakuan } \\
\text { derivative radial. Hasil penelitian ini menunjukkan bahwa derivatif radial } \\
\text { mampu mengidentifikasi keberadaan dan posisi sesar dengan tepat. }\end{array}$} \\
\hline $\begin{array}{l}\text { Kata kunci } \\
\text { Petunjuk penulisan; } \\
\text { Jurnal prisma; } \\
\text { template artikel }\end{array}$ & \\
\hline
\end{tabular}

Sitasi: Ronodirdjo, M.Z., Doyan, A., dkk. (2019). Derivatif Radial Anomali Gravitasi untuk Identifikasi Zona Sesar. Kappa Journal, Pendidikan Fisika, FMIPA, Universitas Hamzanwadi. 3 (2), 63-70

\section{PENDAHULUAN}

Sesar adalah pergeseran tanah (patahan) yang memicu terjadinya gempa bumi. Keberadaan sesar tidak selalu dapat dilihat dengan mata telanjang di atas permukaan bumi, karena lokasi patahan yang jauh dari permukaan. Salah satu cara untuk mengetahui adanya sesar sebagai pemicu gempa bumi adalah dengan cara mengukur anomali gravitasi di atas bidang sesar.

Perkembangan teknologi gravimetri terbaru memungkinkan kita untuk mengukur anomali gravitasi dengan akurasi hingga Gal mikro. Gravitasi mikro mampu mendeteksi anomali 
gravitasi yang sangat kecil seperti anomali akibat pergerseran perlapisan atau sesar. Pengukuran ini juga membutuhkan akurasi tinggi pengukuran posisi hingga sentimeter. Gravitasi mikro mampu mendeteksi anomali gravitasi yang sangat kecil pergeseran yang kecil seklaipun. Salah satu kemampuan gravitasi mikro adalah untuk mendeteksi sesar.

Derivatif radial data gravitasi dapat mempertajam anomali karena perubahan kontras densitas secara lateral. Derivatif horizontal yang dilakukan oleh para peneliti sebelumnya memiliki beberapa kelemahan, yaitu hilangnya nilai-nilai derivatif dalam arah tertentu dan munculnya nilai-nilai yang tidak konsisten pada batas-batas kontras densitas. Untuk mengatasi masalah kelemahan derivatif horizontal yang biasanya hanya pada arah $\mathrm{x}$ atau $\mathrm{y}$, dalam penelitian ini digunakan derivatif yang berbeda, yaitu Derivatif radial.

Derivatif horisontal dan gradien data gravitasi telah digunakan dalam beberapa penelitian untuk mendeteksi batas sumber anomali. Derivatif horisontal pertama dari anomali gravitasi dapat mempertajam penyimpangan anomali, serta derivatif kedua (Tsuboi dan Kato, 1952). Metode derivatif kedua mampu menafsirkan anomali gravitasi di zona antiklin (Rao, ddk., 1971). Derivatif analitik juga digunakan untuk mendeteksi zona sesar. Deteksi dan analisis dilakukan untuk mendapatkan koefisien kedalaman dan amplitudo terkait dengan ketebalan dan kepadatan kontras (Abdelrahman dkk,, 2003). Data gradien gravitasi dapat mendeteksi batas sumber anomali dan memperkirakan kedalaman. Metode ini diterapkan pada anomali gravitasi di wilayah Kozakli-Tengah, Anatolia, Turki (Oruc, dkk., 2010). Perhitungan gradien data gravitasi di cekungan Tuzgolu, Anatolia, Turki telah diuji untuk interpretasi batas-batas struktur geologi. Hasil penelitian ini menunjukkan bahwa perhitungan gradien mampu mendeteksi kesalahan besar dan kecil (Aydogan 2011). Metode derivatif horizontal multi derivatif vertikal (MSHDVD) diuji di zona sesar Foumbon di Kamerun. Hasil tes lapangan menunjukkan bahwa MSHDVD mampu mendeteksi keberadaan kesalahan di Foumbon dengan arah serangan kesalahan N 68o E (Tachtum, 2011). Analisis derivatif vertikal telah digunakan untuk menentukan batas-batas litologi vertikal untuk mempertajam analisis interpretasi gravitasi di Nigus Gusau. Hasilnya menunjukkan bahwa derivatif nol vertikal kedua (SVD) terkait erat dengan batas litologis di daerah tersebut (Aku, 2014). Sudut kemiringan dari derivatif total anomali gravitasi yang telah dinormalisasi telah dilakukan untuk mendeteksi batas-batas struktur geologis. Metode ini telah dilakukan di Laut Oman, sebelah tenggara Iran. Hasil menunjukkan bahwa metode ini lebih baik dalam mendeteksi batas-batas geologis (Askari, 2014). Derivatif vertikal dari data gravitasi 3D telah dilakukan untuk interpretasi struktur geologi. Metode ini telah diuji di daerah yang sangat luas yaitu Jawa Tengah hingga Jawa Timur dan Madura (Wahyudi, 2016). Derivatif horizontal juga digunakan untuk identifikasi sesar (Nurwidyanto, dkk 2014), juga digunakan untuk mempertajam anomali (Pasteka dkk, 2017).

Derivatif radial diusulkan untuk pertama kalinya untuk mengidentifikasi batas sumber anomali. Hasil penelitian menunjukkan bahwa metode ini mampu menunjukkan batas-batas vertikal sumber anomali dengan berbagai keunggulan dibandingkan dengan metode derivatif horisontal biasa (Zuhdi, dkk, 2018). Derivatif Radial adalah derivatif dari anomali gravitasi pada jarak horizontal dalam arah radial dari titik tertentu yang dianggap sebagai pusat anomali. Arah radial dipilih untuk mendapatkan nilai derivatif maksimum dari berbagai anomali. Keuntungan dari derivatif radial dibandingkan dengan derivatif horisontal biasa yang hanya dalam satu arah (x atau y saja) adalah kemampuan untuk mendeteksi batas-batas vertikal berbagai anomali karena lapisan horizontal yang besar dan kemampuan untuk menunjukkan kontras densitas di hampir ke semua arah. 
Tujuan dari penelitian ini adalah menguji efektivitas derivative radial pada data gravitasi untuk identifikasi sesar akibat gempa bumi. Data gravitasi yang digunakan pada penelitian ini adalah data sintetis yang didapatkan dari pemodelan kedepan (forward modelling).

\section{METODE}

Derivatif radial adalah derivatif nilai anomali gravitasi terhadap jarak horizontal dengan arah radial dari suatu titik tertentu. Derivatif horizontal suatu anomali gravitasi adalah derivatif nilai gravitasi dalam arah garis lurus tertentu. Jika garis lurus tersebut memotong secara tegak lurus suatu batas kontras densitas maka nilai derivatifnya akan benilai besar. Dalam banyak kasus diperlukan derivatif yang selalu tegak lurus atau sebisa mungkin mendekati tegak lurus dengan kontras densitas anomali. Untuk keperluan tersebut dibuatlah derivatif radial. Titik pusat derivatif radial dipilih berdasarkan pertimbangan tertentu sehingga titik tersebut dianggap atau dipertimbangkan sebagai pusat anomali yang akan diidentifikasi.

Gambar 1 menunjukkan koordinat kartesian, silinder dan bola serta elemen massa pada koordinat silinder dan bola. Derivatif radial dapat dilakukan pada keempat koordinat tersebut akan tetapi penurunan matematisnya akan lebih mudah jika dilakukan pada koordinat silinder.

Nilai anomali gravitasi $\Delta g_{z}(x, y, z)$ yang disebabkan oleh anomali densitas $\Delta \rho(\alpha, \beta, \gamma)$ dituliskan sebagai :

$\Delta g_{z}(x, y, z)=-K \int_{0}^{\infty} \int_{-\infty-\infty}^{\infty} \int_{-\infty}^{\infty} \frac{\Delta \rho(\alpha, \beta, \gamma)(z-\gamma)}{\left[(x-\alpha)^{2}+(y-\beta)^{2}+(z-\gamma)^{2}\right]^{3 / 2}} d \alpha d \beta d \gamma$

Persamaan 1 dapat diubah ke dalam koordinat silinder, sehingga $\Delta g_{z}(x, y, z)$ menjadi $\Delta g_{z}(R, z, \lambda)$ dan $\Delta \rho\left(R^{\prime}, z^{\prime}, \lambda^{\prime}\right)$, dengan hubungan: $x=R \cos \lambda, y=R \sin \lambda$ dan $z=z$.

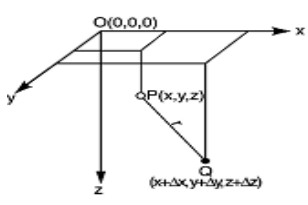

(a)

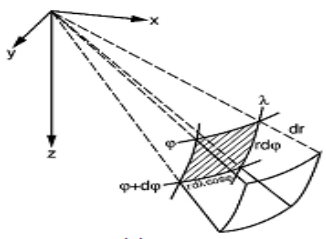

(c)

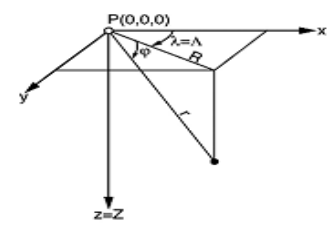

(b)

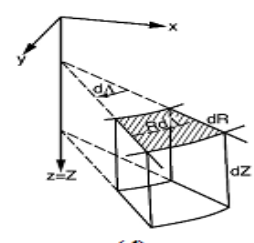

(d)

Gambar 1. Koordinat dari elemen massa; (a) Koordinat Cartesian x, y, z dan hubungan antara 2 titik P dan Q (kiri atas). (b) Koordinat silinder vertikal , R, Z, $\lambda$. (c) Elemen volum koordinat bola. (d) Elemen volum pada koordinat silinder vertikal. (Jacoby dan Smilde,2009)

Sedangkan $\alpha=R \cos \lambda^{\prime}, \beta=R \sin \lambda^{\prime}$ dan $\gamma=z^{\prime}$, dengan elemen massa $\Delta \rho d r d z r d \lambda$ sehingga nilai gravitasi kea rah sumbu z dapat dituliskan sebagai : 
$\Delta g_{z}(R, z, \lambda)=-K \int_{0}^{\infty} \int_{-\infty}^{\infty} \int_{0}^{2 \pi} \frac{\Delta \rho\left(R^{\prime}, z^{\prime}, \lambda^{\prime}\right)\left(z-z^{\prime}\right)}{\left[(x-\alpha)^{2}+(y-\beta)^{2}+(z-\gamma)^{2}\right]^{3 / 2}} r d r d z d \lambda$

First Derivatif radial (FRD) dari anomali gravitasi pada koordinat silinder vertical $\Delta g_{z}(R, z, \lambda)$ secara sederhana dapat dituliskan menjadi :

$$
\begin{aligned}
& F R D=\frac{\partial \Delta g_{z}(R, z, \lambda)}{\partial R} \\
& F R D=\frac{\partial}{\partial R}\left[-K \int_{0}^{\infty} \int_{-\infty}^{\infty} \int_{0}^{\infty \pi} \frac{\Delta \rho\left(R^{\prime}, z^{\prime}, \lambda^{\prime}\right)\left(z-z^{\prime}\right)}{\left[(x-\alpha)^{2}+(y-\beta)^{2}+(z-\gamma)^{2}\right]^{3 / 2}} r d r d z d \lambda\right]
\end{aligned}
$$

Sedangkan second derivatif radial (SRD) secara sederhana dapat dituliskan sebagai:

$$
\begin{aligned}
& S R D=\frac{\partial^{2} \Delta g_{z}(R, z, \lambda)}{\partial R^{2}} \\
& S R D=\frac{\partial^{2}}{\partial^{2} R}\left[-K \int_{0}^{\infty} \int_{-\infty}^{\infty} \int_{0}^{2 \pi} \frac{\Delta \rho\left(R^{\prime}, z^{\prime}, \lambda^{\prime}\right)\left(z-z^{\prime}\right)}{\left[(x-\alpha)^{2}+(y-\beta)^{2}+(z-\gamma)^{2}\right]^{3 / 2}} r d r d z d \lambda\right]
\end{aligned}
$$

Persamaan FRD dan SRD dapat dijabarkan secara analitis jika geometri model dari sumber dapat diketahui dan berbentuk sederhana. Rumusan analitis ini berguna untuk mengetahui perilaku grafis dari anomaly gravitasinya. Persamaan analitis ini juga dibutuhkan dalam pembuatan model inversi radial dari model tersebut.

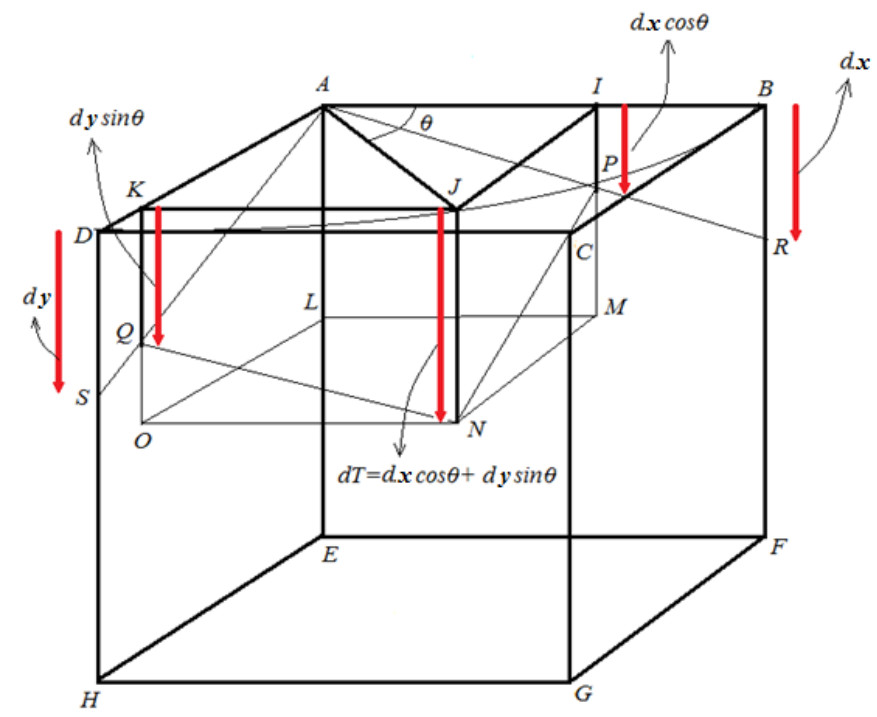

Gambar 2. Diagram bidang untuk Pendekatan Derivatif Radial

Derivatif Radial dapat didekati dengan mengurangkan tiap titik pengukuran kearah tertentu. Derivatif kearah sumbu $X$ didapatkan dengan mengurangkan nilai gravitasi hasil pengukuran dititik $X_{2}$ terhadap nilai gravitasi di titik $X_{1}$ kemudian di bagi dengan jarak $X_{2}$ terhadap $X_{1}$. Untuk mendapatkan nilai derivatif kearah sumbu $Y$ didapatkan dengan mengurangkan nilai 
gravitasi hasil pengukuran dititik $\mathrm{Y}_{2}$ terhadap nilai gravitasi di titik $Y_{1}$ kemudian dengan cara yang sama di bagi dengan jarak $Y_{2}$ terhadap $Y_{1}$.

Dalam banyak kasus, dibutuhkan derivatif yang tidak semata pada arah sumbu $x$ ataupun $y$ tetapi pada arah tertentu, yang sering disebut dengan directional derivatif.

Gambar 2 menunjukkan diagram bidang yang digunakan untuk menghitung derivatif radial. $A B C D, E F G H$ adalah kubus dengan rusuk sepanjang $A B$ yang juga sama dengan $A J$. Titik $A$, $B, C$ dan $D$ adalah titik 2 pengukuran grvaitasi. $A$ ke $B$ adalah garis kearah sumbu $x$ sedangkan $A$ ke $D$ adalah kearah sumbu $y$.

Pada gambar 2 jika beda nilai gravitasi di titik $B$ dengan $A$ adalah $d x$ yang panjang vektornya sebanding dengan $B R$, sedangkan beda nilai gravitasi titik $A$ dengan $D$ adalah $d y$ yang panjang vektornya sepanjang $D S$, maka bidang $A P N Q$ adalah bidang dengan nilai gravitasi yang sama. Jika $d T$ adalah nilai directional derivatif maka:

$$
d T=J N=I P+K Q
$$

dengan dT memiliki panjang vector sama dengan $J N$ yang nilainya sama dengan jumlah $I P$ dan $K Q$.

Panjang IP dapat dijabarkan sebagai berikut:

$$
\frac{I P}{B R}=\frac{A I}{A B}=\frac{A B \cos \theta}{A B}=\cos \theta
$$

dengan $B R=d x$, maka:

$$
I P=d x \cos \theta
$$

Dengan cara yang sama, panjang $K Q$ adalah

$$
\frac{K Q}{D S}=\frac{D A}{K A}=\frac{K A \sin \theta}{K A}=\sin \theta
$$

dengan $K Q=d y$, maka:

$$
K Q=d y \sin \theta
$$

Dengan substitusi ke persamaan (5) maka didapatkan:

$$
d T=d x \cos \theta+d y \sin \theta
$$

Derivatif radial telah dibuat dalam bentuk program computer dalam Bahasa Matlab. Program tersebut dibuat oleh penulis dan catatkan sebagai hak cipta atas nama penulis. Program derivative radial ini kemudian dikenekan pada data sintetis sebagai hasil dari pemodelan kedepan anomali gravitasi akibat sesar.

\section{HASIL DAN PEMBAHASAN}

Sesar dengan komponen vertikal seperti sesar naik dan sesar turun biasanya dengan mudah dikenali lewat anomali gravitasinya, akan tetapi sesar geser tanpa komponen vertikal akan sangat sulit diidentifikasi anomali gravitasinya. 
Untuk mempertajam anomali akibat sesar dengan komponen vertikal dapat dialkukan dengan menderivatif anomali gravitasinya. Nilai derivatif maksimum teridentifikasi sebagai sesar. Pada prinsipnya nilai derivatif akan bernilai maksimum jika derivatif dilakukan secara tegak lurus terhadap sesar. Pada umumnya geomertri sesar berbentuk garis yang hampir lurus. Derivatif radial mampu menunjukkan lokasi sesar dari arah yang tidak diketahui sebelumnya.

Gambar 3. a. menunjukkan respon anomali gravitasi dari forward modelling model sesar, sedangkan gambar 3. b. menunjukkan derivative radial dari anomali model model tersebut;

Model sebesar dibuat berdasarkan struktur patahan (sesar) pada kedalaman 100 meter dengan an pergeseran vertikal sejauh $4 \mathrm{~m}$. Model sesar dibuat pada area seluas $600 \mathrm{~m}$ x 600m dengan arah Strike $180^{\circ}$. Posisi sesar berada pada $\mathrm{x}=500 \mathrm{~m}$ sejajar dengan sumbu y. Dari parameter model tersebut didapatkan anomali gravitasi di atas hanging wall sebesar 0 milli Gal, sedangkan anomali pada daerah diatas foot wall mencapai 60 milli Gal. Perbedaan nilai anomali gravitasi diatas bidang sesar inilah yang yang mengakibatkan adanya nilai derivatif horizontal dengan nilai yang cukup besar.
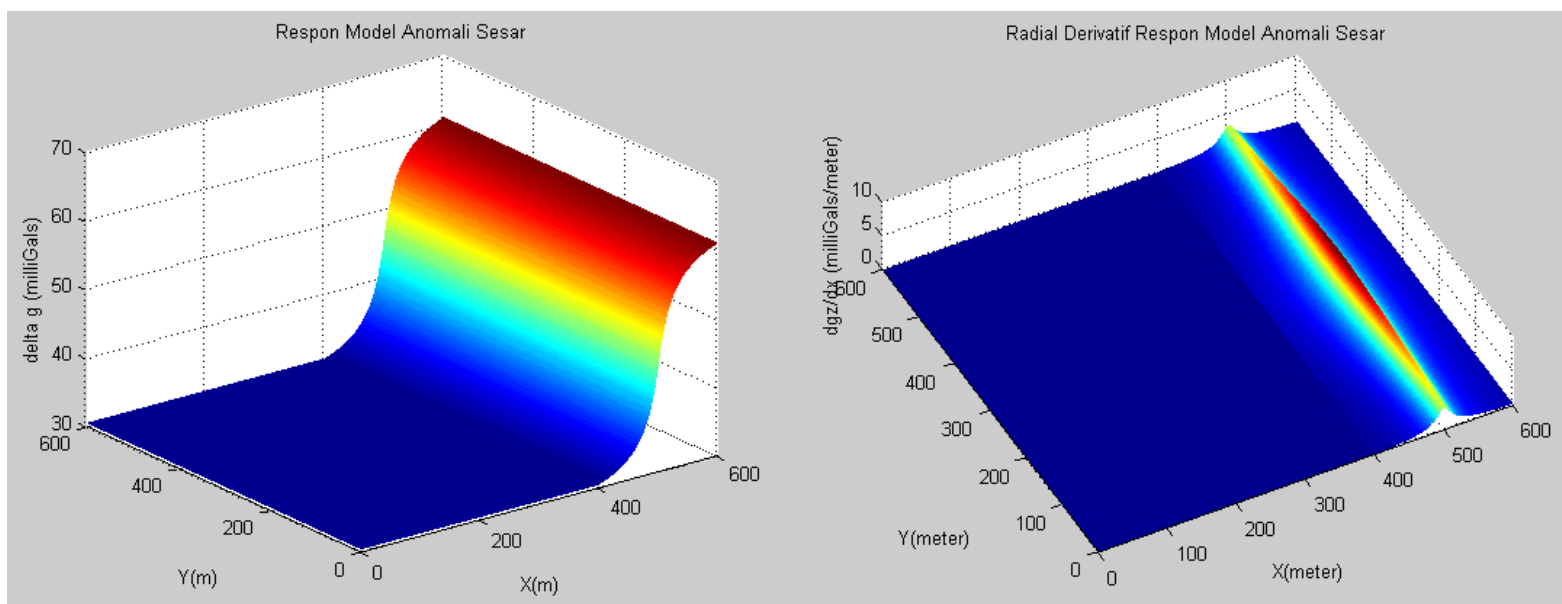

Gambar 3. a. respon forward model anomali gravitasi model sesar b. derivatif radial anomali gravitasi akibat sesar

Derivatif radial respon model anomali sesar ditunjukkan oleh gambar b. Dari gambar ini tampak bahwa derivatif radial mampu memberikan posisi lokasi sesar dengan sangat jelas dan akurat. Nilai maksimum derivative radial sebesar 10 milli Gal per meter didapatkan pada area dengan arah derivatif radial memotong secara tegak lurus strike sesar. Nilai derivatif radial mengecil sesuai dengan sudut yang dibentuk oleh arah radial dengan arah sesar. Semakin kecil sudutnya maka nilai dari derivatif radialnya semakin kecil. Dari hasil tersebut terbukti bahwa derivative Radial mampu mendeteksi posisi sesar dengan tepat.

\section{KESIMPULAN}

Derivatif radial pada penelitian ini terbukti efektif untuk mengidentifikasi keberadaan dan posisi sesar sebagai pemicu gempa bumi dengan akurat. Nilai maksimum derivative radial berada pada arah radial yang tegak lurus memotong bidang sesar. Semakin kecil sudut antara arah radial dengan arah strike sesar, maka semakin kecil pula nilai derivative radialnya.

\section{SARAN}


Untuk penelitian selanjutnya perlu dilakukan pengambilan data gravitasi di lapangan yang dicurigai terdapat struktur sesar, untuk kemudian diberi perlakuan derivatif radial. Dari penelitian lanjutan ini diharapkan derivative radial mampu menunjukkan posisi sesar dari data gravitasi di lapangan.

\section{DAFTAR PUSTAKA}

Abdelrahman, E. M., El-Araby, H. M., El-Araby, T. M., and Abbo-Ezz, E. R., (2003), A least-squares derivatives analysis of gravity anomalies due to faulted thin slabs, Geophysics, Vol. 68, No. 2 (March-April 2003); P. 535-543, 11 Figs., 3 Tables.10.1190/1.1567222

Aku, M. O., (2014), Application Of Second Vertical Derivative Analytical Method To Bouguer Data For The Purpose Of Delineation Of Lithological Boundaries, Science World Journal Vol 9 (No 3) 2014

Askari, A., (2014), Edge detection of gravity anomali sources via the tilt angle, total horizontal derivative, total horizontal derivative of the tilt angle and new normalized total horizontal derivative, Scholars Journal of Engineering and Technology (SJET) ISSN 2321435X (Online) Sch. J. Eng. Tech., 2014; 2(6B):842-846 ISSN 2347-9523 (Print)

Aydogan, D., (2011), Extraction of lineaments from gravity anomali maps using the gradient calculation: Application to Central Anatolia, Earth Planets Space, 63, 903-913, 2011

Jacoby, W.,Smilde, P.L., (2009), Gravity Interpretation Fundamentals and Application of Gravity Inversion and Geological Interpretation, Springer-VerlagBerlin Heidelberg 2009

Nurwidyanto, M.I., Brotopuspito, K.S., Sismanto, Waluyo, (2014), The Sub Surface Modeling of Opak Fault Yogyakarta Region with Inversion Method of Gravity Data, International Journal of Basic \& Applied Sciences IJBAS-IJENS Vol:14 No:06.

Oruc, B., (2010), Edge Detection and Depth Estimation Using a Tilt Angle Map from Gravity Gradient Data of the Kozakl1-Central Anatolia Region, Turkey, Pure Appl. Geophys. 2010 Springer Basel AG DOI 10.1007/s00024-010-0211-0

Pasteka, R., Zahorec, P., Kusnirak, D., Bosansky, M., Papco, J., Szalaiova, V., Krajnak, M., Marusiak, I., Mikuska, J., and Bielik, M., (2017), High resolution Slovak Bouguer gravity anomali map and its enhanced derivative transformations: new possibilities for interpretation of anomalous gravity fields,Contributions to Geophysics and Geodesy Vol. 47/2, 2017 (8194)

Rao, B.S.R., Murthy, I.V.R., and Rao, Y.S.F., (1971), A Second Derivative Method of Interpretation of Gravity Anomalies of Anticlines, Geophysics Department, Andhra University, Waltair, India.

Tatchum, C.N., Tabod, T. C., Koumetio, F., and Manguelle-Dicoum, E., (2011), A Gravity Model Study for Differentiating Vertical and Dipping Geological Contacts with Application to a Bouguer Gravity Anomali Over the Foumban Shear Zone, Cameroon, Geophysica (2011), 47(1-2), 43-55.

Tsuboi and Kato (1952). The First and Second Vertical Derivative of Gravity, Journal of Physics of The Earth. Vol 1, no 2.

Wahyudi. E. J., Kynantoro, Y., and Alawiyah, S., (2016), Second Vertical Derivative Using 3-D Gravity Data for Fault Structure Interpretation, International Conference on Energy 
Sciences (ICES 2016) IOP Publishing IOP Conf. Series: Journal of Physics: Conf. Series 877 (2017) 012039 doi :10.1088/1742-6596/877/1/012039.

Zuhdi, M., Sismanto, Setiawan, A., Setyowiyoto, J., Susilo, A., Sarkowi, M., (2018), Radial Derivative and Radial Inversion For Interpreting 4D Gravity Anomaly Due To Fluids Injection Around Reservoir. Telkomnika, Vol.16, No.6, December 2018, pp.2855 2863 